\title{
Detection of Alpha-1 Antitrypsin Deficiency by Respiratory Therapists: Experience With an Educational Program
}

\author{
James K Stoller MD MSc FAARC, Charlie Strange MD, Laura Schwarz, \\ Thomas J Kallstrom RRT MBA FAARC, and Robert L Chatburn MHHS RRT-NPS FAARC
}

\begin{abstract}
BACKGROUND: Alpha-1 antitrypsin deficiency is under-recognized. We hypothesized that respiratory therapists (RTs) could help improve the detection rate of individuals with alpha-1 antitrypsin deficiency. The American Association for Respiratory Care (AARC) and Alpha-1 Foundation recently collaborated to create an online alpha-1 antitrypsin deficiency training program for RTs. This study aimed to determine (1) the rate of RT enrollment in the training program, (2) the rates of detecting individuals with alpha-1 antitrypsin deficiency referred for testing by RTs who took the online course ("trained RTs"), and (3) the genotype distribution of referred individuals found to have alpha-1 antitrypsin deficiency. METHODS: Patients referred by trained RTs submitted blood samples for alpha-1 antitrypsin deficiency testing through the existing Alpha-1 Coded Testing (ACT) Study. The AARC sent the first 3 digits of trained RTs' zip codes to the study data center. Investigators there matched those zip codes with those of patients in the ACT Study who reported being referred to the study by an RT. The data center determined the number of these patients with alpha-1 antitrypsin deficiency and their genotypes. Investigators then aggregated the data and calculated the RT enrollment rate, the rate of detecting individuals with alpha- 1 antitrypsin deficiency, and the distribution of genotype results. RESULTS: Between July 1, 2012, and June 30, 2013, 378 RTs took the online program (mean 21/mo), and 326 patients reported that they were referred for testing by an RT. Thirty-four percent (111/326) of these referrals were by trained RTs $(6.2 / \mathrm{mo})$. Sixty-two test blood kits were returned by these 111 referred patients and analyzed $(4 / \mathrm{mo})$. Two of these specimens (3.2\%) were from patients identified as having severe alpha-1 antitrypsin deficiency $(\mathrm{PI} * \mathrm{ZZ})$ and one from a patient with PI*SZ (serum level $14 \mu \mathrm{M})$. Twenty-four percent were from PI*MZ heterozygotes. CONCLUSIONS: A program to educate RTs about alpha-1 antitrypsin deficiency was associated with referral of patients for alpha-1 antitrypsin deficiency testing and high rates of detecting individuals with severe alpha-1 antitrypsin deficiency. Key words: alpha-1 antitrypsin deficiency; respiratory therapists; detection. [Respir Care 2014;59(5):667-672. (C) 2014 Daedalus Enterprises]
\end{abstract}

\section{Introduction}

Alpha-1 antitrypsin deficiency is a genetic condition that predisposes to COPD and to liver disease (ie, cirrhosis and hepatocellular carcinoma). Alpha-1 antitrypsin deficiency is common but under-recognized, with long diagnostic delays between the first symptom and initial diagnosis and the frequent need for affected individuals to see multiple healthcare providers before initial recognition. ${ }^{1-6}$

\footnotetext{
affiliated with the American Association for Respiratory Care, Irving, Texas.

This work was supported by a grant from the Alpha-1 Foundation. Dr Stoller has served as a consultant to CSL Behring, Grifols, Pfizer, and Baxter regarding alpha-1 antitrypsin deficiency. The other authors have disclosed no conflicts of interest.
}

\footnotetext{
Dr Stoller is affiliated with the Education Institute and the Departments of Pulmonary Medicine and Critical Care Medicine, Cleveland Clinic, Chatburn is affiliated with the Cleveland Clinic Lerner College of Medicine and the Section of Respiratory Care, Respiratory Institute, Cleveland Clinic, Cleveland, Ohio. Dr Strange is affiliated with the Department of Pulmonary, Critical Care, and Sleep Medicine, and Ms Schwarz is affiliated with the Pulmonary Division, The Medical University of South Carolina, Charleston, South Carolina. Mr Kallstrom is
} 


\section{Detection of Alpha-1 Antitrypsin Deficiency by Respiratory Therapists}

Recent studies of the diagnostic delay interval over the years 1995-2010 indicated that under-recognition persists despite various strategies to enhance recognition. ${ }^{5-7}$ Furthermore, current estimates suggest that fewer than 10,000 of the estimated 100,000 Americans with severe alpha-1 antitrypsin deficiency have been clinically recognized. ${ }^{1}$

The autosomal co-dominant inheritance of alpha-1 antitrypsin deficiency exacerbates the problem of under-recognition because family members of affected individuals may also be at risk. Given that specific therapy that seems to slow the rate of emphysema progression is available, ${ }^{1,8-10}$ strategies to enhance detection are justified and have been proposed. ${ }^{3,7}$ Optimal recognition of alpha-1 antitrypsin deficiency will require enhanced surveillance by all communities of clinicians who see at-risk patients, including pulmonologists; hepatologists; primary care physicians (eg, family physicians and general internists); nurses; and, given their frequent interaction with COPD patients, perhaps especially respiratory therapists (RTs). ${ }^{11-13}$ Indeed, RTs have been shown to effectively participate in the detection of alpha-1 antitrypsin-deficient. ${ }^{14}$ In an earlier Alpha-1 Foundation-sponsored multi-center study, RTs were invited to suggest and arrange alpha- 1 antitrypsin deficiency testing for all patients found to have fixed air-flow obstruction in pulmonary function laboratories. Among the 3,152 patients in this study with fixed air-flow obstruction who were tested for alpha- 1 antitrypsin deficiency, $0.63 \%$ were found to be severely alpha- 1 antitrypsin-deficient (eg, PI*ZZ and $\mathrm{PI} * \mathrm{SZ}$ ), and $\sim 11 \%$ were found to be heterozygotes, thereby establishing that RTs could be effective participants in a targeted detection program.

To extend these findings and to explore more fully the potential impact of RTs in identifying at-risk individuals, we hypothesized that trained RTs could promote alpha-1 antitrypsin testing and thereby improve detection of affected individuals in the course of their routine practices. Specifically, we reasoned that because (1) many patients with COPD see healthcare providers other than pulmonologists (eg, primary care physicians, nurses, and RTs); (2) RTs have been shown to effectively participate in the diagnosis of patients with alpha- 1 antitrypsin deficiency ${ }^{14}$; and (3) RTs can be at the front line of care for such patients in pulmonary function laboratories, in pulmonary rehabilitation, in post-acute settings (eg, long-term acute care and skilled nursing facilities and home care), and in ambulatory care settings, where they are in a position to see and recommend testing for at-risk patients,

Correspondence: James K Stoller MD MSc FAARC, Education Institute, NA22, Cleveland Clinic, 9500 Euclid Avenue, Cleveland, OH 44195. E-mail: stollej@ccf.org.

DOI: $10.4187 /$ respcare. 02817

\section{QUICK LOOK}

\section{Current knowledge}

Alpha-1 antitrypsin deficiency is a genetic condition that predisposes to COPD and liver disease. Alpha- 1 antitrypsin deficiency is common but under-recognized, with long diagnostic delays between the first symptom and initial diagnosis.

\section{What this paper contributes to our knowledge}

A program to educate respiratory therapists about alpha-1 antitrypsin deficiency was associated with increased referral of patients for testing and high rates of detecting individuals with severe alpha-1 antitrypsin deficiency.

RTs could help identify previously unrecognized individuals with COPD related to alpha-1 antitrypsin deficiency. A recent collaboration between the Alpha-1 Foundation and the American Association for Respiratory Care $(\mathrm{AARC})^{15}$ produced an online training program called "Emerging Roles for the Respiratory Therapist in Alpha-1 Antitrypsin Deficiency," 16 which provides a curriculum to enhance RTs' knowledge of alpha- 1 antitrypsin deficiency. Coupled with the availability of free, confidential, at-home testing for alpha- 1 antitrypsin deficiency through the Alpha-1 Coded Testing (ACT) Study, ${ }^{17}$ there was an opportunity to assess whether trained RTs referred COPD patients for alpha- 1 antitrypsin testing and to determine the yield of identification by RTs of severely alpha- 1 antitrypsin-deficient individuals. Outcome measures included the number of trained RTs and the rate at which trained RTs recommended alpha-1 antitrypsin deficiency testing to their patients, as well as the rate at which such tested patients were found to have alpha- 1 antitrypsin deficiency. The purpose of this study was to assess the effectiveness of this strategy for targeted detection of individuals with alpha-1 antitrypsin deficiency.

\section{Methods}

This study was approved by the institutional review board of the Cleveland Clinic. Data-sharing agreements were developed with other collaborating institutions: The Medical University of South Carolina (MUSC) and the AARC.

The online program entitled "Emerging Roles for the Respiratory Therapist in Alpha-1 Antitrypsin Deficiency" consisted of $3 \mathrm{~h}$ of lectures regarding alpha-1 antitrypsin deficiency by 3 pulmonologists (including JKS and CS), followed by an opportunity for the participating RT to take 


\section{Detection of Alpha-1 Antitrypsin Deficiency by Respiratory Therapists}

Table 1. Results of Online Course Training

\begin{tabular}{|c|c|c|c|c|c|c|c|}
\hline & \multicolumn{3}{|c|}{2012} & \multicolumn{2}{|c|}{2013} & \multirow{2}{*}{ Total } & \multirow{2}{*}{ Rate (No./mo) } \\
\hline & Q1 and Q2 & Q3 & Q4 & Q1 & Q2 & & \\
\hline RTs trained & 271 & 32 & 12 & 35 & 28 & 378 & 21 \\
\hline Patients who completed testing & 1204 & 552 & 408 & 705 & 735 & 3604 & 200.2 \\
\hline Patients referred by RT & 117 & 45 & 36 & 60 & 68 & 326 & 18.1 \\
\hline Patients referred by trained $\mathrm{RT}^{*}$ & 22 & 20 & 8 & 32 & 29 & 111 & 6.2 \\
\hline \multicolumn{8}{|c|}{$\begin{array}{l}\text { * Zip code of patient matches zip code of RT supplied by the American Association for Respiratory Care. } \\
\mathrm{Q}=\text { quarter (ie, 3-month period) } \\
\mathrm{RTs}=\text { respiratory therapists }\end{array}$} \\
\hline
\end{tabular}

an online examination. Successful passage of the online examination (ie, $\geq 67 \%$ correct) resulted in issuance to the $\mathrm{RT}$ of a certificate of competence from the AARC and the Alpha-1 Foundation, which were the sponsoring organizations. A nominal fee of $\$ 25$ for AARC members was assessed to defray administrative expenses.

The ACT Study ${ }^{17}$ provides consenting individuals the opportunity to be tested for alpha-1 antitrypsin deficiency in a confidential manner at home. Specifically, online informed consent sent to the MUSC, the sponsoring institution of the ACT Study, is followed by a demographic questionnaire including zip code. Participants then receive a mailed information form and a coded blood test kit on which a dried blood specimen is collected and sent to the University of Florida Alpha-1 Antitrypsin Genetics Laboratory, which is the testing laboratory. ${ }^{7}$ Specimens are eluted to determine a serum level of alpha-1 antitrypsin (by nephelometry) and a genotype (by polymerase-chain-reaction testing for the $\mathrm{Z}$ and $\mathrm{S}$ alleles). A confidential report is then sent to the patient's home containing the results and an explanation of the results written in lay language.

RTs began enrolling in the "Emerging Roles for the Respiratory Therapist in Alpha-1 Antitrypsin Deficiency" online program after January 1, 2012, and the study interval was defined a priori to be the 1-year interval between July 1, 2012, and June 30, 2013. As part of the curriculum of the online program, RTs who took the online course (hereafter called "trained RTs") were made aware of the ACT Study and invited to refer any patients they deemed likely candidates (ie, with established COPD) to participate in the ACT Study to learn whether they had alpha-1 antitrypsin deficiency.

Under a stipulation of the ACT Study, ${ }^{17}$ the data analysis required preserving the confidentiality of ACT Study participants, thereby requiring that results of the ACT testing could be provided only to investigators at the Cleveland Clinic (JKS and RC) in an aggregated de-identified format. To do so, a data-sharing agreement was required between the three participating institutions: Cleveland Clinic, MUSC, and AARC. The AARC housed and cosponsored the online course and sent zip codes of partic- ipating RTs to the MUSC, where the principal investigator of the ACT Study (CS) works. Reasoning that RTs seeing and referring COPD patients to the ACT Study would reside in the same geographic area, zip codes were used to link the RT recommending alpha- 1 antitrypsin testing with the patient who underwent testing. Specifically, when patients seeking ACT testing indicated on the ACT Study information form that they were referred for testing by an RT and when a trained RT's zip code corresponded with the patient's (ie, agreement in the first 3 digits of the zip code), that specimen was considered to be one that was referred by a trained RT. Aggregated de-identified data on the results of ACT Study participants, especially the number of such patients and the alpha- 1 antitrypsin genotypes of submitted specimens, were sent to the Cleveland Clinic, where the data were analyzed.

Statistical analysis was conducted using chi-square tests. The statistical software used was SigmaPlot for Windows 11.0 (Systat Software, San Jose, California). Values of $P<.05$ were deemed statistically significant.

\section{Results}

As presented in Table 1, 378 RTs completed the online program (ie, were trained RTs) between July 1, 2012, and June 30, 2013 (mean $21 \mathrm{RTs} / \mathrm{mo}$ ). Three-hundred twentysix patients reported that they were referred for alpha-1 antitrypsin testing by an RT. Thirty-four percent (111/326) of these referrals were from trained RTs (mean 6.2 patients/mo). Table 2 shows the results of blood test kit analyses for patients who were referred by trained RTs. Of the 111 referred patients who requested test kits through the ACT Study, blood test kit specimens were submitted by 62 ( $55.8 \%$ at a mean rate of 4 specimens received per mo). Among these 62 (Table 3), two (3.2\%) were found to have severe alpha- 1 antitrypsin deficiency, which was defined as having a serum alpha- 1 antitrypsin level below the "protective threshold" value of $11 \mu \mathrm{M} .^{1,2}$ Both of these patients were $\mathrm{PI} * \mathrm{ZZ}$. A third $\mathrm{PI} * \mathrm{SZ}$ patient had a serum alpha- 1 antitrypsin level slightly exceeding the protective threshold (ie, $14 \mu \mathrm{M}$ ). Thirty-two percent of patients re- 


\section{Detection of Alpha-1 Antitrypsin Deficiency by Respiratory Therapists}

Table 2. Results of Blood Test Kit Analyses for Patients Who Were Referred by Trained Respiratory Therapists

\begin{tabular}{|c|c|c|c|c|c|c|c|}
\hline \multirow{2}{*}{ Genotype } & \multicolumn{3}{|c|}{2012} & \multicolumn{2}{|c|}{2013} & \multirow{2}{*}{$\begin{array}{c}\text { Total } \\
(\%)\end{array}$} & \multirow{2}{*}{$\begin{array}{c}\text { Rate } \\
\text { (No./mo) }\end{array}$} \\
\hline & Q1 and Q2 & Q3 & Q4 & Q1 & Q2 & & \\
\hline $\mathrm{PI} * \mathrm{MM}$ & 11 & 9 & 4 & 8 & 10 & 67.7 & 2.3 \\
\hline $\mathrm{PI} * \mathrm{MS}$ & 1 & 0 & 0 & 0 & 0 & 1.6 & 0.2 \\
\hline $\mathrm{PI}^{*} \mathrm{MZ}$ & 5 & 0 & 0 & 6 & 4 & 24.2 & 1.3 \\
\hline PI*M null & 0 & 0 & 0 & 0 & 0 & 0.0 & 0.0 \\
\hline $\mathrm{PI}{ }^{*} \mathrm{SS}$ & 0 & 1 & 0 & 0 & 0 & 1.6 & 0.2 \\
\hline $\mathrm{PI} * \mathrm{SZ}$ & 0 & 0 & 0 & 1 & 0 & 1.6 & 0.2 \\
\hline $\mathrm{PI} * \mathrm{ZZ}$ & 1 & 0 & 0 & 1 & 0 & 3.2 & 0.2 \\
\hline Total per quarter & 18 & 10 & 4 & 16 & 14 & 100 & \\
\hline Total all & 62 & & & & & & \\
\hline
\end{tabular}

$\mathrm{Q}=$ quarter (ie, 3-month period)

Table 3. Activity and Results of Alpha-1 Antitrypsin Deficiency Testing in the Trained Respiratory Therapist Group Versus Those Respiratory Therapists Who Did Not Take the Online Course

\begin{tabular}{|c|c|c|c|}
\hline & \multicolumn{2}{|c|}{ RT Online Course Status } & \multirow{2}{*}{$P$} \\
\hline & Trained & Untrained & \\
\hline Patients referred $(n)$ & 111 & 215 & N/A \\
\hline Patients not referred $(n)$ & 215 & N/A & \\
\hline Referred $(\%)$ & 34.0 & & \\
\hline Total referred $(n)$ & 326 & & \\
\hline Specimens received $(n)$ & 62 & 109 & 0.70 \\
\hline Patients referred $(n)$ & 111 & 215 & \\
\hline Specimens received $(\%)$ & 55.9 & 50.7 & \\
\hline Total specimens received $(n)$ & 171 & & \\
\hline Severe AAT deficiency $(n)$ & 2 & 4 & 0.78 \\
\hline Specimens received $(n)$ & 62 & 109 & \\
\hline Severe AAT deficiency $(\%)$ & 3.2 & 3.7 & \\
\hline $\begin{array}{l}\text { Patients with } \geq 1 \text { abnormal AAT } \\
\text { allele }(n)^{*}\end{array}$ & 20 & 52 & 0.26 \\
\hline $\begin{array}{l}\text { Patients with } 0 \text { abnormal AAT } \\
\text { alleles }(n)\end{array}$ & 62 & 109 & \\
\hline Abnormal AAT allele (\%) & 32.3 & 47.7 & \\
\hline Patients with PI*MZ genotype $(n)$ & 15 & 27 & 0.91 \\
\hline Patients without PI*MZ genotype $(n)$ & 62 & 109 & \\
\hline $\mathrm{PI} * \mathrm{MZ}$ genotype $(\%)$ & 24.2 & 24.8 & \\
\hline $\begin{array}{l}\text { * Included alleles: } \mathrm{S}, \mathrm{Z} \text {, and null } \\
\mathrm{RT}=\text { respiratory therapist } \\
\mathrm{N} / \mathrm{A}=\text { data not available } \\
\mathrm{AAT}=\text { alpha- } 1 \text { antitrypsin }\end{array}$ & & & \\
\hline
\end{tabular}

ferred by trained RTs carried at least one abnormal alpha-1 antitrypsin allele; $24.2 \%$ were $\mathrm{PI} * \mathrm{MZ}$.

Of the 215 patients who requested ACT Study test kits and who were referred by RTs who had not participated in the online program, blood specimens were submitted by $109(50.7 \%)$. Of these 109, $4(3.7 \%)$ indicated severe al- pha-1 antitrypsin deficiency: 3 individuals were PI*ZZ, and one was PI*Z null. A fifth PI*SZ individual was not severely deficient (serum alpha-1 antitrypsin level of 12.2 $\mu \mathrm{M})$. Forty-seven percent of patients carried at least one abnormal alpha- 1 antitrypsin allele (ie, anything other than $\mathrm{PI} * \mathrm{MM}) ; 24.8 \%$ were PI*MZ.

\section{Discussion}

The main findings of this proof-of-concept study are that an online program to instruct RTs regarding diagnosis and management of alpha-1 antitrypsin deficiency was widely used in the first year of implementation $(n=378$ participants); that RTs who took the online course did suggest alpha- 1 antitrypsin testing to their patients; and that, despite only a small number of submitted specimens over the year of study, the yield of detecting individuals with severe alpha- 1 antitrypsin deficiency was higher $(3.2 \%)$ than in many previously reported targeted detection studies. ${ }^{7}$ In addition, the yield of detecting PI*MZ individuals was very high $(24.2 \%)$.

As a comparison regarding the impact of the online course, RTs who did not take the online course also referred their COPD patients to the ACT Study over the study interval, and the rate of detecting severely alpha-1 antitrypsin-deficient individuals was similar to that in the trained RT group (3.7\%). In this group, the rate of detecting PI*MZ individuals was similarly high (24.8\%).

In the context of the hypothesis that persisting underrecognition of alpha- 1 antitrypsin deficiency can be addressed by novel strategies (eg, encouraging RTs to advise patients to undergo testing using free, confidential, at-home blood test kits), our findings reinforce the important role that RTs may play in helping to detect patients with alpha-1 antitrypsin deficiency. The finding that the rates of detecting severely alpha- 1 antitrypsin-deficient individuals among the trained RTs and those RTs who did not take the online course were similarly high $(3.2 \%$ and $3.7 \%$, respectively) suggests that the key element in driving detection of affected individuals was RT involvement in targeted detection rather than course completion. Although taking the online course likely enhanced RTs' knowledge of alpha-1 antitrypsin deficiency, RTs' awareness of the option for their patients to be tested using the ACT Study alone seemed to account for the high rate of detecting severely deficient individuals in this study.

In demonstrating a novel and efficient strategy for detecting individuals with severe alpha- 1 antitrypsin deficiency, this study extends experience with targeted alpha-1 antitrypsin deficiency detection strategies. As reviewed previously, ${ }^{3}$ many such strategies have been undertaken to date, including attempts to raise awareness of alpha-1 antitrypsin deficiency among primary care physicians and RTs using various instructional methods (eg, continuing 


\section{Detection of Alpha-1 Antitrypsin Deficiency by Respiratory Therapists}

medical education lectures, targeted publications); making free test kits available for use in physician offices as well as confidential in-home testing ${ }^{17}$; and interest in developing a point-of-care laboratory test for alpha- 1 antitrypsin, including writing recommendations to test for alpha-1 antitrypsin deficiency on the pulmonary function test reports of patients with fixed air-flow obstruction on spirometry, ${ }^{18}$ issuing prompts within the electronic medical record for alpha-1 antitrypsin testing of patients with fixed air-flow obstruction, ${ }^{19,20}$ and reconsidering screening of newborns for alpha-1 antitrypsin deficiency. ${ }^{21,22}$ The prevalence of PI*ZZ individuals detected in 9 prior targeted detection reports has been variable (range $0-12 \%$ ), with 6 of the 9 studies reporting rates of PI*ZZ detected individuals less than the $3.2 \%$ rate detected by trained RTs in the present study. One of the earlier 9 studies $^{23}$ reported an identical rate of $3.2 \%$.

The present study also extends earlier efforts by linking the role of RTs as caregivers who encounter COPD patients in many settings with a strategy by which alpha-1 antitrypsin testing can be done free and confidentially and that does not require specific physician intervention to perform testing. In this regard, the testing strategy here amplifies the benefits that RTs have conferred in other clinical interventions (eg, administering respiratory care protocols for liberation from mechanical ventilation or for allocating in-patient respiratory care $)^{24-26}$ and demonstrates the potential benefits of having allied health providers function at the "top of their licenses" in the new model of value-based healthcare.

Several limitations of the study merit discussion. First, the requirement to preserve patient anonymity in the ACT Study and the need for data-sharing agreements to conduct the study called for a novel strategy to link the referring trained RT with the received specimens by concordant zip codes (rather than actual names or specific identifiers). Hence, misclassification is possible. Although it seems highly likely that a referring trained RT was the same RT who recommended testing for a patient whose specimen was submitted from a matching zip code, it is possible that specimens could be misattributed. For example, if the referring trained RT happened to live and practice in different states when referring the patient to the ACT Study, the specimen would not be linked to the RT. In this circumstance, the analysis would underestimate the prevalence of testing recommended by trained RTs, and the frequency of detecting severely alpha-1 antitrypsin-deficient individuals could also be underestimated. Conversely, if a trained RT happened to live in the same state as a patient submitting a specimen but was not the actual RT who saw the patient and recommended alpha-1 antitrypsin testing, the specimen could be mistakenly attributed to the RT, thereby potentially inflating the rates. That said, the latter scenario seems unlikely.
A second limitation is that with only 62 submitted specimens from referred patients over the 1-year study interval, the study size was small, lessening the robustness of the prevalence estimates. That said, the observed rates of detecting 3.2\% severely alpha- 1 antitrypsin-deficient subjects and $32.3 \%$ of patients with at least one abnormal alpha-1 antitrypsin allele (including 24.2\% PI*MZ individuals) far exceed the usual observed frequencies in targeted detection studies ${ }^{7}$ or the estimated population prevalence rates for these alpha- 1 antitrypsin variants.

The significance of this study is that it offers support for broader efforts to train RTs to help detect individuals with alpha-1 antitrypsin deficiency, thereby potentially helping to address the persisting under-recognition of alpha- 1 antitrypsin deficiency. Because many patients with COPD are not seen by pulmonologists but may see RTs (eg, in pulmonary function laboratories or during pulmonary rehabilitation), the strategy of encouraging RTs to recommend testing holds special promise. Of course, replication of these results in a larger series will be important.

In conclusion, this study has shown that a program that informs RTs about alpha-1 antitrypsin deficiency was associated with referral of patients for alpha- 1 antitrypsin deficiency testing and a high rate of detecting individuals with severe alpha- 1 antitrypsin deficiency. To the extent that the rate of detecting severely alpha-1 antitrypsin-deficient patients here exceeds that in most prior reports of targeted testing, these findings support the ideas that RTs can play important roles in enhancing detection of individuals with alpha- 1 antitrypsin deficiency and that training RTs is an effective measure to enhance alpha- 1 antitrypsin deficiency detection.

\section{REFERENCES}

1. Stoller JK, Snider GL, Brantly M, Fallat RJ, Stockley RA, American Thoracic Society/European Respiratory Society Statement: standards for the diagnosis and management of individuals with alpha- 1 antitrypsin deficiency: executive summary. Am J Respir Crit Care Med 2003;168(7):816-900

2. Stoller JK, Aboussouan L. Concise clinical review: alpha-1 antitrypsin deficiency. Am J Respir Crit Care Med 2012;185(3):246-259.

3. Aboussouan LS, Stoller JK. Detection of alpha-1 antitrypsin deficiency: a review. Respir Med 2009;103(3):335-341.

4. Stoller JK, Smith P, Yang P, Spray J. Physical and social impact of alpha-1 antitrypsin deficiency: results of a survey. Cleve Clin J Med 1994;61(6):461-467.

5. Stoller JK, Sandhaus RA, Turino G, Dickson R, Rodgers K, Strange C. Delay in diagnosis of alpha-1 antitrypsin deficiency: a continuing problem. Chest 2005;128(4):1989-1994.

6. Campos MA, Wanner A, Zhang G, Sandhaus RA. Trends in the diagnosis of symptomatic patients with alpha- 1 antitrypsin deficiency between 1968 and 2003. Chest 2005;128(3):1179-1186.

7. Stoller JK, Brantly M. The challenge of detecting alpha-1 antitrypsin deficiency. COPD 2013;10 (1 Suppl):26-34.

8. Dirksen A, Dijkman JH, Madsen F, Stoel B, Hutchison DC, Ulrik $\mathrm{CS}$, et al. A randomized clinical trial of alpha-1 antitrypsin augmen- 


\section{Detection of Alpha-1 Antitrypsin Deficiency by Respiratory Therapists}

tation therapy. Am J Respir Crit Care Med 1999;160(5 Pt 1):14681472 .

9. Dirksen A, Piitulainen E, Parr DG, Deng C, Wencker M, Shaker SB, Stockley RA. Exploring the role of CT densitometry: a randomised study of augmentation therapy in alpha-1 antitrypsin deficiency. Eur Respir J 2009;33(6):1345-1353.

10. Chapman KR, Stockley RA, Dawkins C, Wilkes MM, Navickis RJ. Augmentation therapy for alpha-1 antitrypsin deficiency: a metaanalysis. COPD 2009;6(3):177-184.

11. Stoller JK, Fromer L, Brantly M, Stocks J, Strange C. Primary care diagnosis of alpha-1 antitrypsin deficiency: issues and opportunities. Cleve Clin J Med 2007;74(12):869-874.

12. Stoller JK. Emerging role of the respiratory therapist and the diagnosis of alpha-1 antitrypsin deficiency. AARC Times 2012;36:1113.

13. Stoller JK. Key current clinical issues in alpha-1 antitrypsin deficiency. Respir Care 2003;48(12):1216-1224.

14. Rahaghi FF, Sandhaus RA, Brantly ML, Rouhani F, Campos MA, Strange C, et al. The prevalence of alpha- 1 antitrypsin deficiency among patients found to have airflow obstruction. COPD 2012;9(4): 352-358.

15. Walsh JW, Snider GL, Stoller JK. A review of the Alpha-1 Foundation: formation, impact, and critical success factors. Respir Care 2006;51(5):526-531.

16. American Association for Respiratory Care. Emerging roles for the respiratory therapist in alpha-1 antitrypsin deficiency. http://www. aarc.org/education/alpha1_course. Accessed on July 18, 2013.

17. Strange C, Dickson R, Carter C, Carpenter MJ, Holladay B, Lundquist R, Brantly ML. Genetic testing for alpha-1 antitrypsin deficiency. Genet Med 2004;6(4):204-210.
18. Rahaghi F, Ortega I, Rahaghi N, Zamudio J, Oliveira E, Ramirez J, Smolley L, Stoller JK. The impact of including physician alert accompanying pulmonary function (PFT) results on testing for detection of alpha-1 antitrypsin deficiency. COPD 2009;6(1):26-30

19. Jain A, McCarthy K, Xu M, Stoller JK. Impact of clinical support system in an electronic health record to enhance detection of alpha-1 antitrypsin deficiency. Chest 2011;140(1):198-204.

20. Campos M, Hagenlocker B, Martinez N, Lupena H, Caceres F, Gallo De Moraes A, et al. Impact of an electronic medical record clinical reminder to improve detection of COPD and alpha-1 antitrypsin deficiency in the Veterans Administration (VA) system. Am J Respir Crit Care Med 2011;183:A5356.

21. O'Brien ML, Buist NRM, Murphey WH. Neonatal screening for alpha-1 antitrypsin deficiency. J Pediatrics 1978;92(6):1006-1010.

22. Sveger T. Liver disease in alpha- 1 antitrypsin deficiency detected by screening of 200,000 infants. N Engl J Med 1976;294(24):13161321.

23. Brantly ML, Mishra VS, Viranovskaya N, Zienko L, Corcoran V, Leonard S, et al. Statewide targeted screening and detection of AAT deficiency. Am J Respir Crit Care Med 2003;167:A222.

24. Stoller JK, Mascha EJ, Kester L, Haney D. Randomized trial of physician- vs. respiratory therapy consult-directed respiratory care. Am J Respir Crit Care Med 1998;158(4):1068-1075.

25. Kollef MH, Shapiro SD, Silver P, St. John RE, Prentice D, Sauer S, et al. A randomized, controlled trial of protocol-directed versus physician-directed weaning from mechanical ventilation. Crit Care Med 1997;25(4):567-574

26. Kollef MH, Shapiro SD, Clinkscale D, Cracchiolo L, Clayton D, Wilner R, Hossin L. The effect of respiratory therapist-initiated treatment protocols on patient outcomes and resource utilization. Chest 2000;117(2):467-475.

This article is approved for Continuing Respiratory Care Education credit. For information and to obtain your CRCE

(free to AARC members) visit

\section{www.rcjournal.com}

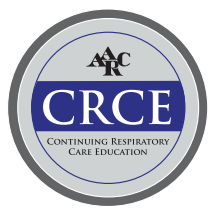

